\title{
O princípio responsabilidade e a crítica ao transumanismo ${ }^{1}$
}

\section{The responsibility principle and the criticism of transhumanism}

क. $10.21680 / 1983-2109.2021 v 28 n 55 I D 19447$

Leonardo Nunes Camargo Pontifícia Universidade Católica do Paraná (PUC-PR) (1) 0000-0002-3370-1327 leonardo_bigmusic@yahoo.com.br

Resumo: $O$ objetivo desse artigo é mostrar como o princípio responsabilidade de Hans Jonas, formulado numa dimensão ontológica e ética, enfrenta as teses do transumanismo em relação ao human enhancement. Embora Hans Jonas pensasse que a racionalidade representa o último grau de desenvolvimento da liberdade numa abordagem fenomenológica da vida, com o surgimento do(s) transumanismo(s) e a ideia de que podemos aprimorar o ser humano utilizando procedimentos tecnocientíficos, sustentamos que a autenticidade humana encontra sua maior expressão no conceito de responsabilidade. Isto é, uma vez que o transumanismo, com seus adeptos mais utópicos, pressupõe o surgimento de uma nova era da espécie humana, precisamos de um novo princípio ético capaz de frear os novos poderes tecnológicos da humanidade a fim de garantir a existência e a integridade da vida de forma genuína e autêntica.

\footnotetext{
1 O presente trabalho foi realizado com apoio da Coordenação de Aperfeiçoamento de Pessoal de Nível Superior Brasil (CAPES) Código de Financiamento 001.
} 
Palavras-chave: Responsabilidade; Transumanismo; Liberdade; Autenticidade.

\begin{abstract}
The aim of this paper is to show how Hans Jonas' responsibility principle, formulated in an ontological and ethical dimension, faces the theses of transhumanism in relation to human enhancement. Although Hans Jonas thought that rationality represented the last degree of development of freedom in a phenomenological approach to life, with the emergence of transhumanism (s) and the idea that we can enhance human beings using technoscientific procedures, we maintain that authenticity Humanity finds its greatest expression in the concept of responsibility. That is, since transhumanism, with its most utopian adherents, presupposes the emergence of a new age of the human species, we need a new ethical principle capable of curbing the new technological powers of humanity in order to ensure the existence and integrity of life. in a genuine and authentic way.
\end{abstract}

Keywords: Responsibility; Transhumanism; Freedom; Authenticity.

\title{
Introdução
}

A partir de meados do século XX, a sociedade viu florescer certos perigos iminentes que a tecnologia produziu, como por exemplo: a manipulação genética, o prolongamento da vida, o controle de comportamento, tratamentos e procedimentos a fim de retardar o envelhecimento, a criogenia, as alterações na relação homem e trabalho, a ameaça à democracia, a eugenia, entre tantos outros. No entanto, não se trata de perigos e ameaças repentinas e de curto prazo, mas, pelo contrário, são perigos que ameaçam a existência e a integridade da vida. É neste cenário contemporâneo, que a engenharia genética se mostra como uma utopia, à medida que pretende reconfigurar a imagem de homem. Porém junto com esses novos poderes, surge a necessidade de estabelecer uma imagem de homem que tem em sua base a não-arbitrariedade, para Jonas "com o eclipse da revelação, essa imagem é responsabilidade única da filosofia" (Jonas, 2017, p.17). 
As novas tecnologias contemporâneas que passaram a modificar a natureza humana, a ponto de reconfigurá-la e aprimorá-la, provocou uma mudança na natureza da ação humana, por isso é fundamental um novo princípio ético, fundamentado do ponto de vista ontológico, epistemológico e moral. Obviamente essa mudança não diz respeito apenas à inserção de novos objetos na vida humana, mas de um ponto de vista qualitativo representa uma modificação no agir do ser.

Sófocles em um famoso canto (ou coro) de sua tragédia Antígona retrata a grandeza do homem e sua engenhosidade diante da ordem cósmica, a partir do qual Jonas assinala que, "o homem é o criador da vida enquanto humana" (Jonas, 2017, p.25). Ora, a exceção era a morte, mas mesmo assim o homem continuava pequeno diante da natureza. Fato é que com a moderna tecnologia esse homem domina e explora a natureza, a ponto de subjugá-la a seus desejos, e a própria morte, que era exceção naquele período, passa a figurar entre os alvos a serem superados pelo novo ser humano. Fereidoun M. Esfandiary (autonomeado FM 2030), um pensador transumanista do século passado, escreve sobre a morte nos seguintes termos: "Se é natural morrer, ao inferno com a natureza. Por que se submeter a sua tirania? Devemos nos elevar acima da natureza. Devemos nos recusar a morrer" (FM 2030, 1989).

Apesar da existência de muitas correntes do transumanismo, razão pela qual o modo correto de mencioná-lo seria transumanismos, podemos dizer que há uma espécie de fio condutor epistemológico e ontológico que perpassa todos, que é o desejo de imortalidade. No século XXI, a promessa de superação da morte e o prolongamento da vida se tornaram o principal desafio e o ápice da conquista aspirada por certas empresas e grandes corporações, como o GAFA e o BATX.

Mas o que é o transumanismo? Em linhas gerais, podemos dizer que se trata de um exercício filosófico, cultural e intelectual, de diversas áreas do saber, que tem como principal projeto o 
aprimoramento da humanidade, em outras palavras, o (s) transumanismo (s) quer dar um upgrade na constituição física, psíquica, emocional e por que não, moral do homem, libertando-o das limitações impostas pela natureza. No entanto, o(s) transumanismo(s) é(são) em nossa concepção, apenas um estágio de transição ao que chamamos de pós-humano, neste novo estágio a humanidade seria totalmente destituída de suas características atuais, de modo que não saberemos se, de fato, seremos ainda humanos. Para Nick Bostrom, atualmente, um dos principais defensores do transumanismo "teremos a opção de estender nossas capacidades intelectuais, físicas, emocionais e espirituais muito além daquilo que parece possível hoje em dia. Sairemos então da infância da humanidade para entrar na era transumana" (2002).

Para mostrar que existe uma espécie de confusão por parte dos próprios defensores do transumanismo, Savulescu, outro defensor do transumanismo, nos diz que estamos caminhando para uma era pós-humana ao invés de transumana, isto é, ao procurar responder sobre o que seremos no futuro, ou ainda, o que seria os seres póshumanos, o autor sugere que seremos "seres originalmente 'evoluídos' ou desenvolvidos a partir de seres humanos, mas significativamente diferentes, de tal modo que não são mais humanos em qualquer aspecto significativo" (Savulescu, 2009, p. 214).

Nesse contexto transumanista, é importante notar que existe uma "tendência espontânea" (Ferry, 2018, p.2), que Hans Jonas já havia denunciado em 1979, em seu O Princípio Responsabilidade: ensaio de uma ética para a civilização tecnológica, que aponta a impossibilidade de as éticas tradicionais frearem os impulsos tecnológicos da técnica moderna, e a crença de que a essência do ser humano e até mesmo da natureza, era algo eterno e imutável. Porém, atualmente, a medicina já não condiz com a ideia de apenas curar e restabelecer um estado de harmonia do corpo, sua função é de aprimorar o ser humano e os seres vivos, isto é, a cada dia, ela busca métodos e procedimentos capazes de aumentar nossas capacidades. 
É importante ressaltar uma diferenciação que usamos nesse trabalho em relação ao termo enhancement, isto é, em nossas pesquisas o termo que melhor se adequa a tradução é aprimoramento ao contrário de melhoramento. Luc Ferry em sua obra $A$ revolução transumanista, apesar de ciente da diferença dos termos, entende o transumanismo como um projeto que visa a "melhoria da humanidade atual" (2018, p.1). Melhoria, nos parece, tem a ver com uma espécie de restabelecimento e adequação a um estado natural. Já o aprimoramento é antes uma adição de aspectos que até então não pertencem à natureza humana.

O escritor Nicholas Agar em sua obra Truly Human Enhancement: a philosophical defense of limits propõe uma análise minuciosa do termo e sugere que, apesar de facilmente confundirmos enhancement com improvement, e da variedade linguística de interpretações que o termo pode vir a representar, defende que o mais correto é afirmar que o aprimoramento consiste em propor modificações genéticas que estão além das normas humanas, ou seja, o aprimoramento é a manipulação que implicará em resultados que extrapolam os limites naturais do que é ser humano. Notavelmente isso vai ao encontro das propostas do enhancement Project proposto pelos transumanistas.

Portanto, nesse trabalho assumimos a posição de que o aprimoramento consiste na capacidade de manipulação para além das normas humanas (human norms). Essas normas que traduzimos literalmente são questões biológicas naturais que constituem o humano. Nesse sentido, vemos que nessa definição há um contraste com a noção de terapia na arte médica, uma vez que esta busca por meio de procedimentos e intervenções médicas apenas restaurar e/ou preservar níveis de funcionamentos normais de um corpo vivo sob o aspecto biológico. Poderíamos citar diversos exemplos utilizados por médicos para restaurar um estado de normalidade no corpo do indivíduo, como a insulina para diabéticos. Desse modo, numa perspectiva que acreditamos não ser suficiente para abarcar o conceito de enhancement, principalmente 
dentro do transumanismo, poderíamos dizer que o uso terapêutico se aproxima do enhancement como um improvement. Mas precisamos lembrar que há casos em que o uso de um medicamento para fins terapêuticos pode vir a se tornar um enhancement.

Neste trabalho, o que nos interessa é frisar que o enhancement Project sustentado e defendido pelos transumanistas constitui um perigo à autenticidade da vida em geral e à integridade da vida humana, uma vez que tal projeto ameaça superar a linha tênue que a natureza vem construindo ao longo de milhões de anos. Muitos defensores do(s) movimento(s) dirão que as superações dos limites biológicos da humanidade são o próximo passo que a natureza demoraria anos para dar, ou que essa aceleração nas mudanças psicofísicas que podemos operar, foram concedidas pela própria natureza, isto é, os desejos e capacidades que adquirimos graças ao desenvolvimento tecnológico e científico não passam de um dom que a natureza nos concedeu e que nos tornou capazes de moldar a própria espécie.

Julian Huxley, autor do livro New Bottles for new Wine, antes de estabelecer as bases de uma nova era de evolução da espécie humana, como resultado de um longo processo da natureza, e assim chamar esse novo estágio de transumanismo, acreditava que um dos feitos mais notáveis do século XX foi o desvelamento do homem enquanto único ser vivo capaz de se tornar o senhor e o modelador da própria existência.

Gilbert Hottois, por sua vez, em sua obra $O$ transumanismo é um humanismo, não acredita que podemos creditar os ideais transumanistas apenas a um processo evolutivo da espécie, é preciso mensurar que tal movimento se consolida no século XXI por ser o momento que tornou possível promover uma sinergia entre tecnologia, ciência, credos religiosos, articulações filosóficas e humanistas. Nesse sentido, vale lembrar a forma como Pico Della Mirandola em sua Oração sobre a dignidade do homem, ainda no século $\mathrm{XV}$, escreve ao se referir ao homem e fundando as bases 
epistemológicas e ontológicas daquilo que conhecemos hoje como transumanismo:

A natureza bem definida dos outros seres é refreada por leis por nós prescritas. Tu, pelo contrário, não constrangido por nenhuma limitação, determiná-la-ás para ti, segundo o teu arbítrio, a cujo poder te entreguei. Coloquei-te no meio do mundo para que daí possas olhar melhor tudo o que há no mundo. Não te fizemos celeste nem terreno, nem mortal nem imortal, a fim de que tu, árbitro e soberano artífice de ti mesmo, te plasmasses e te informasses, na forma que tivesses seguramente escolhido. Poderás degenerar até os seres que são as bestas, poderás regenerar-te até às realidades superiores que são divinas, por decisão do teu ânimo. (Mirandola, 1989, p.52-53).

Esse movimento de transcendência (no sentido de que o homem passaria a controlar sua natureza própria) da humanidade, enquanto espécie, é entendida por Julian Huxley como uma nova crença, de modo que nos contornos transumanistas na atualidade, a possibilidade de aperfeiçoamento dos seres humanos se tornou um dever ético e moral. Nick Bostrom afirma que lutar contra nosso maior mal que é a morte, se tornou uma "urgência moral" (Bostrom, 2011, p.179).

O problema transumanista ganha notoriedade na contemporaneidade, pelo fato de que vivemos numa era em que a biotecnologia avança de forma impensável há alguns anos e ressignifica toda a forma de pensar e viver da sociedade. Se vivemos numa era de artificialização da vida e até mesmo de ameaça a nosso patrimônio genético, precisamos saber quais os limites éticos que devem ser impostos a esses novos ideais utópicos que pretendem manipular a vida e conduzi-la a um novo estágio da humanidade. Obviamente que apenas uma análise ética não é suficiente para impor barreiras ao transumanismo, é necessário reinterpretar a posição ontológica do homem no cosmos e assim estabelecer as bases e princípios de uma fenomenologia da vida.

Por isso, nosso trabalho parte do pressuposto de que precisamos de um princípio que abarca consigo tanto uma dimensão ontológica como uma dimensão ética. Com Hans Jonas, sustentamos que esse princípio pode ser encontrado no conceito de 
responsabilidade, uma vez que, se precisamos salvaguardar algo que é próprio da natureza humana, isto é, uma imagem para as gerações futuras, precisamos lembrar do que temos de mais autêntico, que é nossa capacidade de nos responsabilizar pelo fenômeno vida, que tem como marca fundamental a liberdade.

\section{Liberdade e o caráter transcendente da vida}

O conceito de liberdade em Hans Jonas extrapola a dimensão fenomênica da consciência humana e é colocada no reino da vida, enquanto marca existencial desse fenômeno. Para o autor alemão, a liberdade irá encontrar seu mais elevado grau de desenvolvimento na responsabilidade, dimensão substancial e formal da vida humana. Resta, então, saber como Jonas disserta e analisa a concepção de liberdade.

A liberdade na filosofia jonasiana é entendida como um "conceito guia capaz de orientar-nos na tarefa de interpretar a vida" (Jonas, 2004, p.106). Se quisermos pensar numa nova posição do homem no cosmos, isto é, como agente portador da responsabilidade, e por isso, responsável por salvaguardar as gerações futuras de possíveis ameaças que atingem sua integridade e autenticidade, precisamos repensar o fenômeno vida, e atribuir a ele, uma característica que, até então, era exclusiva do ser humano, desse modo, a liberdade passa a ser vista como uma auto causalidade.

Jonas sustenta que o surgimento da vida se dá enquanto um acontecimento que parte de uma escolha da própria vida, uma decisão que a mesma teve de tomar a fim de manter sua "sobrevivência". Através de uma ação primária, a substância viva ao se separar da interação geral das coisas da natureza, portanto, ao se desprender da matéria inerte, introduziu no mundo a tensão entre ser e não ser. Jean Monod confirma a tese jonasiana, "apenas o acaso é a origem de cada novidade, de cada criação da biosfera. $\mathrm{O}$ acaso puro, apenas o acaso, a liberdade absoluta, mas cega, para a raiz própria do prodigioso edifício da evolução" (Monod, 1976, 
p.96). Com essa escolha (ação primária) surge uma série de consequências com as quais a vida terá que conviver, contradições que, até então, eram impostas apenas ao ser humano, como autonomia e dependência, eu e mundo, relação e isolamento, entre outros $^{2}$.

A vida, desse modo, está marcada pela liberdade (ou seja, ela escolhe viver, dá o "sim" necessário para continuar a existir) e pela necessidade (caso a vida não quisesse viver, não optasse pelo sim, ela teria escolhido a morte, a sua negação). A cada novo estágio que a vida opta por um sim, mais livre ela se torna, entretanto, junto com sua possibilidade de conquista há, em mesmo grau, o risco de fracasso, portanto, "onde habita a liberdade também cresce o perigo" (Oliveira et al. , 2015, p. 23).

A liberdade na história da vida representa o desprendimento que o organismo (forma viva) tem em relação à matéria. $O$ ser vivo não é simplesmente seu corpo material, há algo nele que o transcende. Essa liberdade surge no metabolismo como independência precária do orgânico para com a matéria, e termina nos níveis mais elevados da evolução orgânica, ou seja, passa pela imediaticidade das plantas, pelas capacidades de sensação, movimento e emoção dos animais e chega à autoconsciência dos seres humanos, último estágio da escala evolutiva segundo Jonas.

Para ele, a liberdade encontra seu substrato básico no metabolismo, que se revela como "um poder da forma orgânica, o poder de mudar sua matéria, mas que, ao mesmo tempo implica também a inevitável necessidade de fazer exatamente isto" (Jonas, 2004, p.107). A vida é livre e como tal "carrega nos ombros o fardo da necessidade" (Jonas, 2004, p.14). Trata-se de uma "liberdade dialética" (Jonas, 2004, p.106): ao mesmo tempo em

${ }^{2}$ A polaridade fundamental que Jonas considera é a entre ser e não ser. O organismo deve constantemente afirmar sua identidade, fazendo um esforço constante para adiar sua contradição eminente, o não ser, uma vez que, este é a regra das coisas do universo. Entretanto, apesar de todo esforço que o organismo empreende ao se opor a sua contradição, no fim ele sucumbirá perante a morte. Dessa forma, a mortalidade torna-se característica essencial da própria vida. 
que é livre, a vida também é obrigada à liberdade, na medida em que precisa intercambiar com o ambiente para que possa continuar vivendo. Desse modo, a atividade metabolizante torna-se, no pensamento de Jonas, a característica fundamental da existência orgânica e a forma elementar da liberdade. Porém, audácia da liberdade da forma viva traz consigo o fardo da necessidade.

O próprio ser orgânico passa a ser pensado como uma atividade, isto é, a vida, a fim de se afirmar, precisa constantemente manter uma relação equilibrada entre as polaridades em que ela se encontra. Por isso, para Jonas, o organismo é a parte visível do universo na qual esse modo de ser se realiza, ou seja, é onde a vida se manifesta.

Em sua carta de 25 de fevereiro de 1944, destinada a sua esposa Lore Jonas, durante a Segunda Guerra Mundial, presente em sua obra Memorias, Jonas escreve que as coisas materiais possuem identidades simples e imediatas, completamente vazias, dessa forma sua identidade não se transmuta ao longo do tempo. De um ponto de vista gnosiológico, podemos afirmar uma identidade na partícula material, isto é, graças à persistência material que se mantém ao longo do espaço e do tempo sua identidade permanece inalterada. Pelo fato de a identificarmos nas várias regiões do espaço que ela pode ocupar, podemos afirmar uma identidade na matéria, "sua trajetória ininterrupta no contínuo espaço-temporal é aqui o único critério de identidade" (Jonas, 1998, p.26).

Qualquer partícula de matéria, independentemente de sua posição espaço temporal, possui uma auto identidade vazia em relação à substância, só pode ser afirmada e percebida devido a sua persistência e duração ao longo do tempo, sua mesmidade é uma função da continuidade das dimensões espaciais e temporais; sua forma é um acidente, totalmente dependente da matéria, portanto, sem uma realidade própria. São alguns fatores, como a duração, a mesmidade e a perseverança da matéria, que criam 
certa identidade de um corpo material, mas que não deve ser confundido com a identidade orgânica.

A identidade do ser vivo se constitui através de uma atividade incessante, resultado de uma autoconstituição e autorrenovação de sua forma, que vão se originando mediante sua atividade. Segundo Jonas,

Sua existência é uma função e não substância; sua duração é acontecimento e não precisamente perseverança, uma vez que a perseverança é abandonada uma e outra vez num processo de autogeração. (...) A identidade fixa, material, da partícula, se opõe à identidade dinâmica, funcional do ser vivo (Jonas, 2005, p.381-382) ${ }^{3}$.

Desta maneira, a existência do ser orgânico não é algo dado, como acontece num corpo material, mas resultado de sua própria ação. O ser vivo está a todo o momento se constituindo e se auto realizando, ou seja, ele está em constante atividade. Para entendermos a identidade do ser vivo, precisamos lembrar a inversão ontológica que Jonas propôs, ou seja, o fato de que a forma é um caráter essencial da vida e não a matéria. Do ponto de vista do metabolismo, a forma está relacionada com a essência e a matéria se tornou o acidente do ser, em outras palavras, na configuração orgânica do ser, o elemento orgânico deixa de ser substância e passa a ser atividade. A liberdade está, nesse caso, ligada à forma e essa, encontra-se entrelaçada com o metabolismo.

${ }^{3}$ Esta passagem foi traduzida do espanhol da obra Memorias com a seguinte redação: "Su existencia es función y no sustância; su duración es acontecimento e no precisamente perseverancia, mientras que la mera perseverancia es abandonada una y otra vez en el proceso de su autogeneración (...). La identidade fija, material, de la partícula, se opone a la identidade dinámica, funcional de lo vivo" [grifo nosso] (Jonas, 2004, p. 381-382). Destacamos o termo "autogeneración", para evidenciarmos que, ao invés do que sugere a edição francesa Souvenirs que traduz o termo como "auto-instituição", a ideia de autogeração em Jonas, também está vinculado a uma ideia de autopoiése, ou seja, a vida se autoconstitui e se autoafirma como atividade. Portanto, nos parece que a quirela da tradução do termo que evidenciamos não altera o significado que Jonas atribui ao fenômeno vida. 
O caráter da autonomia da forma viva se revela e se constitui não de uma só vez, ou seja, ela não recebe todo seu conteúdo material em um único momento da sua existência. Sua estrutura é constituída por momentos de trocas de matérias com o mundo no qual ela vive, através de um movimento constante de receber aquilo que lhe é necessário e eliminar o que não é mais. Contudo, ao longo desse processo, a forma viva continua sendo ela mesma e se moldando nos traços de um ser orgânico. Segundo Jonas, “a forma viva é apenas um ponto de transição da matéria que a atravessa segundo suas próprias leis e cuja unidade aparente não é mais que um estado configurativo de sua diversidade" (Jonas, 2005, p.383).

Nesse novo nível da vida, a forma é o estágio em que a matéria passa a fazer parte da própria vida, é ela que atrai e expulsa a própria matéria de si mesma em relação ao mundo. Enquanto no corpo material a forma nada mais é que um estágio de troca da matéria permanente, na forma viva ela atua de maneira organizativa, mesmo quando seus conteúdos materiais não sofrem mutações no ser e continuam sendo idênticos. Sendo assim, mesmo a forma sendo um ponto de passagem da matéria, devemos afirmar que, a sucessão de conteúdos materiais que se configuraram são fases transitórias em um processo da forma.

Essa constante mudança de matéria que é o próprio metabolismo, responsável por manter o ser vivo, coloca a seguinte questão: como um ser que muda constantemente seu conteúdo material pode ser o mesmo? Como podemos afirmar uma identidade em algo que não permanece o mesmo? A reposta é que a forma viva, que se refere à essência do organismo, acompanha o fluxo de mudanças da matéria, ou seja, a essência orgânica do ser vivo permanece sempre a mesma. Segundo Jonas, essa forma viva que acompanha a matéria, que permanece no ser vivo, é uma conquista da liberdade, uma "forma autônoma, característica essencial da vida" (Jonas em Lopes, 2014, p.169). O desafio de Jonas fica explícito aqui: pensar as contradições da liberdade humana no nível da vida, essa é a releitura biológica que o autor 
propõe quando escreve os diferentes textos que vão, depois, compor a sua obra The Phenomenon of Life: toward a philosophical a biology.

A forma viva, como pensada por Jonas, é organizativa e ativa por si só, é a própria forma que realiza as trocas materiais com o meio ambiente, ela está em um constante autoconstituir-se. A autointegração da vida nos leva ao conceito ontológico de indivíduo, que faltava para afirmarmos a identidade do orgânico, pois, junto com o indivíduo ontológico, está a existência subjetiva do próprio sujeito. "Porque sua "liberdade" é sua necessidade, o "poder" se transforma em "dever" quando o que importa é ser, e em toda vida é deste "ser" que se trata [...]. Possuindo o poder, tem que exercê-lo para existir, e não pode cessar de fazê-lo sem que cesse de existir: liberdade para o fazer, mas não para o omitir" (Jonas, 2004, p.107).

A vida possui necessidade do mundo, está relacionada com ele, depende dele, está disposta ao encontro dele, experimenta o mundo e através dessa "experiência, possui o mundo" (Jonas, 2004, p.108). O mundo torna-se elemento constitutivo da atividade orgânica, enquanto o ser vivo depender da matéria para se renovar, o mundo se abrirá para a forma viva a fim de suprir suas necessidades, que deve ser entendida aqui como carência ${ }^{4}$.

A vida precisa ampliar seu horizonte de atuação, fazendo do mundo, além de uma necessidade orgânica da matéria, uma

${ }^{4}$ Jonas se refere à carência como uma das propriedades do ser orgânico, como uma característica exclusiva da vida, portanto, não pertencente ao resto da realidade. De acordo com o autor, um átomo por ser um elemento autossuficiente existe independentemente do que aconteça com o mundo a sua volta, entretanto, "a essência do organismo, ao contrário, inclui a não autarquia" (Jonas, 1998, p.93). Por poder usar o mundo, a vida encontra sua polaridade, ou seja, sua necessidade, se ela pode atuar no mundo ela deve, pois se não fizer pode deixar de existir. Dessa forma, a vida é dependente da sua própria ação. "A dependência que impera aqui é a dívida que a substância primordial assumiu quando, ao invés de permanecer na matéria inerte, se aventurou ao iniciar o caminho da identidade orgânica, uma identidade que se constitui a si mesma" (Jonas, 1998, p.93). 
fundamentação da liberdade material. Desse modo, podemos afirmar uma transcendência da vida, que vai além de sua relação consigo mesma, ou seja, ela "quer ultrapassar os próprios limites e abrir-se para o mundo" (Oliveira et al, 2015, p. 23).

Neste autotranscender através da condição de necessidade fundamentase a transcendência essencial de toda vida, que nos estágios mais elevados lhe abre um mundo cada vez mais amplo. O ser dependente indica o campo de suas possíveis realizações, desta maneira criando a intencionalidade como um caráter básico de toda a vida (Jonas, 2004, p.109).

De acordo com Comín, a liberdade deve ser entendida como "constante tensão e relação de reciprocidade com a necessidade" (2005, p. 45). Dessa forma, quando o organismo necessita de algo e passa a ter interesse por aquilo, novos horizontes se abrem para que esta carência possa ser suprida. O próprio Jonas afirma, "quando falamos de transcendência da vida, queremos dizer que ela mantém um horizonte, ou horizontes, além de sua identidade puntiforme" (Jonas, 2004, p.110).

Junto com essa transcendência e essa abertura ao mundo estranho na qual a liberdade ontológica passa a depender da matéria e juntas alcançam novos estágios e graus de ascensão de liberdade, precisamos considerar a dimensão da interioridade. Ela está presente nas ações que acontecem dentro do organismo e que, de certo modo, abriga o interesse absoluto do organismo em sua existência e sua vontade de autopreservação.

A autotranscendência pode ser entendida como um movimento compulsivo ligado à atividade, graças a uma necessidade orgânica orientada para fora, através de um lado passivo dessa transcendência que são as sensações capturadas ao longo do processo. Esse processo "coloca a vida no estado de ser 'eletiva' e 'informada', em lugar de ser apenas uma cega dinâmica" (Jonas, 2004, p.110). Desta maneira, a função da interioridade nessa etapa da autotranscendência da vida é a de comunicação entre as coisas. 
$\mathrm{Na}$ transcendência da vida encontramos o essencial para a atividade metabólica, que Jonas traduz da seguinte forma:

Os dois horizontes para os quais a vida constantemente se transcende podem ser reduzidos à relação transitória da forma orgânica para com sua própria matéria. A orientação interior para a fase imediatamente seguinte de um ser que precisa manter-se a si mesmo constitui o tempo biológico; a orientação exterior para o não-ele-mesmo igualmente presente que contém a matéria necessária para sua continuação constitui o espaço biológico (Jonas, 2004, p.110-111).

No horizonte do tempo, que marca a transcendência do orgânico e sua continuação, o futuro é mais fundamental que a historicidade vivida pelo ser orgânico. Contudo, não podemos descartar a vivência no passado e a memória, pois elas são essenciais para garantir a identidade, uma vez que esse passado se transforma em condição para a continuidade interior do ser vivo. Enquanto o futuro se abre como "impulso da vida".

De certa maneira, esse transcender da vida implica estar disposto a uma relação. Ao posso que através do metabolismo o organismo assimila o conteúdo externo a fim de suprir suas necessidades, esse mesmo ser vivo precisa dominar a natureza. Graças a essa abertura do organismo ao mundo, o ser vivo passa a reconhecer o outro. Dessa forma, se o metabolismo é a primeira característica da vida, isto é, o primeiro passo que a forma viva dá em direção ao mundo externo, a fim de suprir suas necessidades, graças a essa abertura, esse passo em direção ao que é estranho, faz com que o organismo passe a se relacionar. E, segundo Jonas, "viver é essencialmente estar relacionado com algo" (Jonas, 2004, p.15). Em Organismo e liberdade [Organismus und Freiheit] de 1973, Jonas resume essa ideia sobre a vida:

Por carecer do mundo, ela [a vida] está voltada para ele; voltada (ou aberta) para ele, está relacionada com ele; relacionada com ele, está pronta para o encontro; pronta para o encontro, ela é capaz de experiência; na auto aquisição ativa de seu ser, primariamente através da auto ativação do fornecimento de matéria, ela promove por si mesma permanentemente o encontro, atualiza a possibilidade de experiência; em função de sua experiência 'possui' o 'mundo' (Jonas em Lopes, 2014, p. 184). 
Por ser capaz de possuir o mundo e se relacionar com ele, o organismo também pode se isolar. $\mathrm{O}$ auto isolamento é muito mais uma necessidade da forma viva do que uma falta de relação com o mundo. Sem dúvida, a capacidade de isolamento e sua transcendência em direção ao mundo (ambiente) revela a dicotomia e a polarização da vida, que a acompanha desde seu surgimento, ou seja, estamos falando da antinomia entre eu e mundo.

Toda ação do organismo no mundo externo necessita de informações. O primeiro fator a enviar essas informações ao ser vivo são as sensações, elas permitem que a vida não siga simplesmente um dinamismo cego, mas, pelo contrário, seja capaz de selecionar suas reais carências e de ser informada. O próprio ato de procurar alimento faz com que a vida se torne discriminativa, o organismo precisa reconhecer o que pode e deve ser apropriado e assimilado. Até mesmo quando o ser vivo está ameaçado, ele necessita de informações para se defender.

Precisamos lembrar que a vida não é marcada apenas pelas adversidades, que o organismo pode encontrar, ela deve também desfrutar de uma socialidade, ou seja, Jonas defende que a mensagem transmitida também pode ser de outro ser que queria "ajudar", por exemplo, na captura de nutrientes para sua preservação. O autor em um curso de $1966^{5}$, afirma que a existência com os outros é essencial ao indivíduo orgânico. A vida necessita de algum tipo de trocas e comunicação entre os membros da espécie, nem que seja apenas para fins reprodutivos.

Quando afirmamos que, para Jonas, tanto a captura de alimentos quanto a reprodução são indispensáveis para se manter respectivamente o organismo e a espécie, fica claro a aproximação que o autor alemão tinha com a filosofia de Aristóteles, pois para o Estagirita essas duas características são essenciais à vida. Mesmo com o papel que a socialidade desempenha na vida do ser vivo o

${ }^{5}$ Esse curso foi realizado entre os anos de 1966 e 1977, e encontra-se no Arquivo Hans Jonas na Universidade em Konstanz e tem como título Life and Organism. 
metabolismo ainda continua sendo a camada básica da existência da vida. E graças ao metabolismo a vida se revela "como movimento, conhecimento e emoção, a um só tempo" (Lopes, 2014, p. 188). Ainda sobre o metabolismo, Jonas em seu texto Biological Foundations of Individuality, de 1968, ressalta a sua importância para o desenvolvido de certas funções e aptidões em outras camadas da vida:

O mero fenômeno do metabolismo, sempre considerado como não mais do que o nível elementar que serve de base, e fornece energia, para as mais diferentes funções superiores da vida (tais como percepção, locomoção e desejo), de fato inclui em sua própria constituição primária a fundamentação de todas aquelas funções como tais, que podem ou não se desenvolver sobre esta base (Jonas em Lopes, 2014, p.188).

O metabolismo é a primeira forma que a vida encontra para perpetuar e autotranscender em direção a estágios mais elevados e complexos, de modo que, a cada novo estágio mais liberdade e mais individualidade. Sendo assim, também, mais mediação do organismo em relação ao mundo, novas carências e necessidades surgirão e se unirão à camada metabólica básica.

O tempo biológico está aberto à experiência orgânica, abrange algo que está por acontecer, ou seja, a cada momento num futuro próximo, a continuidade orgânica está disposta a satisfazer suas carências daquele momento. Assim, "a vida está voltada tanto para frente como para fora" (Jonas, 2004, p.110). A transcendência temporal está voltada ao futuro, para o logo mais. Esse não pode ser confundido com o tempo físico, pois, para Jonas, no ser vivo os momentos temporais estão interligados pela interioridade orgânica. Portanto, a vida só se volta para fora porque através de sua necessidade e liberdade ela precisa olhar também para frente.

\section{A responsabilidade no horizonte fenomenológico da vida}

Estabelecidas as bases epistemológicas e ontológicas que colocam a liberdade no âmbito do fenômeno vida, agora, tentaremos mostrar como a responsabilidade, enquanto dimensão 
ontológica e ética, se instala na escala evolutiva jonasiana como sendo o último estágio de desenvolvimento das capacidades e função da vida orgânica. Antes disso, precisamos assinalar dois fatos importantes nessa nossa análise: o primeiro refere-se ao salto quantitativo e qualitativo que ocorre nessa abordagem: a escala evolutiva ascendente dos graus de liberdade parte do metabolismo, passa pelo movimento e apetite, pela sensação e percepção, imaginação, arte e conceito. Assim, após mostrar como a liberdade é colocada no início dessa escala, saltaremos para o elemento central desse trabalho, para apontarmos nosso segundo fato: que consiste em colocar a responsabilidade nesse horizonte fenomenológico. Ou seja, para além do que Jonas postula em sua obra The Phenomenon of life que o conceito, portanto, a racionalidade humana, seria o último estágio dessa escala, sustentamos que devido às novas dimensões globais e temporais que a biotecnologia adquiriu nos últimos anos, tendo encontrado sua expressão maior no transumanismo, a responsabilidade é o elemento preponderante, própria da dimensão humana e da autenticidade da vida que melhor enfrenta as teses de aprimoramento do transumanismo.

A proposta jonasiana de fundamentar um novo princípio ético solidificado em bases ontológicas, a partir de uma releitura fenomenológica da vida é, portanto, levada a cabo pelo autor alemão sobre as bases de uma natureza orgânica ( $c f$. Bohler, 2019, p.203). Essa posição é evidenciada já na obra The Phenomenon of life, em que Jonas sinaliza que "uma filosofia da vida tem como objeto a filosofia do organismo e a filosofia do espírito" (Jonas, 2004, p.11), de modo que pensar o espírito é colocá-lo nas bases orgânicas mais elementares da vida e, assim, é nessa base orgânica que também encontramos a liberdade, consequentemente a raiz da responsabilidade.

Resta saber como podemos fundamentar essa responsabilidade enquanto dimensão própria do humano? Quais as bases que sustentam a responsabilidade enquanto liberdade do e para $o$ agir? 
Dois elementos que fundamentam o princípio responsabilidade precisam ser analisados aqui, trata-se do conceito de futurologia comparativa e a heurística do temor. Para Jonas, como a tecnologia moderna apresenta como principais características a ambivalência de seus efeitos e extrapola as dimensões globais de tempo e espaço, precisamos de uma nova ciência, tanto no aspecto prático como ideal, capaz de superar o tempo presente, isto é, o autor propõe uma ciência de "previsão hipotética" (Jonas, 2006, p.70). Em outras palavras, frente ao futuro ameaçado, e o fato de não termos ainda experimentado na história humana, os efeitos da manipulação genética e aprimoramento humano, o primeiro dever da ética da responsabilidade é visualizar os efeitos da tecnologia no longo prazo. Para tanto, devemos ser capazes de antecipar ou imaginar um tipo de mal capaz de mobilizar a nossa ação.

Assim, adentramos ao segundo dever da ética do futuro que é mobilizar o sentimento correto, se formos capazes de imaginar um mal que ameaça a autenticidade da vida e da humanidade, precisamos de um sentimento que desperte no ser humano a capacidade de ação, desse modo, podemos dizer que, no reino do ser humano, o agir se insere como atividade capaz de salvaguardar a vida futura. Esse sentimento só pode ser o temor, ou seja, um sentimento que, ao mesmo tempo, em que alerta para os perigos, nos impulsiona a agir. Desse modo, tanto a futurologia comparativa como a heurística do temor tem como objetivo orientar a ação do homem, ainda que de maneira hipotética. De acordo com Oswaldo Giacoia Junior:

É nesse sentido que o medo pode ter um efeito heurístico, levando-nos a procurar e descobrir novas possibilidades e estilos de vida, assim também como produzir o efeito benéfico de chamar-nos a responsabilidade perante nós mesmos e as próximas gerações de seres humanos e não humanos. (Giacoia Junior, 2019, p.220).

O caráter coletivo da responsabilidade é evidente nas palavras de Giacoia Junior, pois somos responsáveis não somente pela vida humana, mas também pelos seres não humanos. Desse modo, o 
alcance do princípio responsabilidade, de fato, visa assegurar a permanência de uma autêntica vida sobre a Terra.

Uma vez que "ser responsável por", do ponto de vista ético, implica uma capacidade de poder decidir por uma ação, podemos dizer que a "responsabilidade é produto da liberdade". Jonas nos diz: "é esse o fardo da liberdade próprio a um sujeito ativo: eu sou responsável por meus atos enquanto tais (mesmo por minha omissão), e pouco me importa a circunstância de quem demanda a resposta, se agora ou mais tarde" (Jonas em Pinsart, 2019, p.7677). Desse modo, não quer dizer que o ser humano pode optar ou não pela responsabilidade, essa se impõe à natureza humana. Assim como a ferramenta, a imagem e a tumba, a responsabilidade também está inserida na escala evolutiva de desenvolvimento, no homem, das funções e capacidades do orgânico; desse modo, a responsabilidade torna-se a essência do ser humano.

Para Jonas, em sua obra Matéria, Espírito e Criação, um dos aspectos que permitem uma diferenciação antropológica é o salto qualitativo da subjetividade que podemos encontrar no ser humano. Isto é, da mesma forma que a tumba é um artefato da transanimalidade, a experiência subjetiva de um eu substancial permite ao homem tornar-se o sujeito agente da ação moral. É nesse sentido que a responsabilidade assume o status de complemento da liberdade que nos impele à ação.

Ainda nessa obra, de acordo com Jonas, encontramos um tipo de liberdade que pesa sob a existência humana, a liberdade moral, para o autor a mais transcendente e perigosa, "pois é também a liberdade de negar-se, de surdez voluntária e, inclusive, de escolher uma contra opção que pode chegar até o mal radical que (como temos aprendido) pode, ademais, adornar-se com a aparência do Bem supremo" (Jonas, 2010, p.31).

Aqui adentramos num ponto importante da obra $O$ princípio responsabilidade: ensaio de uma ética para a civilização tecnológica, que diz respeito à heurística do temor. A fim de estabelecer as bases de tal princípio ético - uma vez que as teses 
transumanistas sobre o enhancement ainda não são capazes de prever todos os riscos e efeitos que tais experimentos poderão causar ao ser humano - que tem como objetivo salvaguardar a existência das gerações futuras, Jonas propõe que precisamos de uma "previsão de uma deformação do homem" (Jonas, 2006, p.70). Precisamos de um tipo de saber que gere no ser humano uma ideia clara daquilo que o ameaça e assim o convoque à ação. Assim como a tecnologia hoje confere poderes inimagináveis ao ser humano,

O conhecimento do bem e do mal, o poder de distingui-los, é também a capacidade para o bem e o mal. Fica claro que o "eros" em ação enquanto fator de impulso necessário em qualquer escolha entre bens, não oferece ainda, mesmo como guia, garantia alguma para vislumbrar e perseguir seu verdadeiro objeto - mesmo e especialmente quanto em grande medida ele se tornou, como nos homens, uma questão de ver. [grifo do autor] (Jonas, 2010, p.31).

Pinsart, no seu verbete do Vocabulário Hans Jonas, completa "não somente a capacidade de ser responsável obriga a exercer essa capacidade sob o olhar de todos os objetos contingentes da ação, mas ela impõe igualmente a responsabilidade de colocar-se, ela mesma, como seu próprio objeto de exercício" (Pinsart, 2019, p.137). O próprio Jonas nos alerta n' $O$ Princípio Responsabilidade: ensaio de uma ética para a civilização tecnológica sobre o primeiro imperativo da ética do futuro: que exista uma humanidade! Por isso, não podemos transferir a responsabilidade da existência da humanidade às futuras gerações uma vez, que a existência delas, depende de nós. Além disso, a responsabilidade tem como dever zelar pela imagem do ser humano, ou seja, por sua representação no mundo, tanto hoje como no futuro. Assim, seguindo o pensamento de Pinsart, uma vez que a responsabilidade tem como dever garantir sua presença, ela também garantiria a liberdade. Desse modo, evidencia-se o caráter ontológico e ético da responsabilidade, ou seja, ao passo que a responsabilidade, numa dimensão que chamamos de substancial, deve garantir que exista uma humanidade; ela também afirma, numa dimensão formal, que é preciso que haja 
uma vida humana autêntica. Essas duas características da responsabilidade são complementares entre si.

Ao formular o princípio responsabilidade, Jonas evidencia que a atividade reflexiva do sujeito cognoscente, ao passo que transforma o homem no único indivíduo no reino do Ser como portador da responsabilidade, também o torna objeto de "avaliação e vontade axiológica" (Jonas, 2010, p.32). Esse sujeito ao tornar-se responsável por um objeto externo a ele, "também implica por si só o cuidado bem pelo interior, e pela possibilidade e obrigatoriedade do valor da própria pessoa" (Jonas, 2010, p.32).

\section{Considerações finais}

Lembremos que, para Jonas, a afirmação original do Ser é, de fato, sua tendência a um propósito e o primeiro propósito de todo ser é continuar a ser. Ser é melhor que não ser, ter fins é melhor do que não ter, e se auto-afimar em primeiro lugar, a fim de continuar lá. É essa superioridade de ter fins em relação a não ter fim algum, de se opor ao não-ser, que constitui o axioma ontológico fundamental que permite que Jonas interprete o propósito intrínseco de ser, não apenas como um fato, mas também como um valor. Se ser é preferível a não ser, então, isso significa que o propósito para o qual o próprio ser tende, isto é, a sua conservação, é também um valor a ser salvaguardado. Por isso, mesmo diante da precariedade e vulnerabilidade que a existência pode apresentar, a liberdade vai se constituindo e aumentando em diferentes graus perpassando o vegetal, o animal até culminar no ser humano.

Esse valor a ser salvaguardado tem a ver com a imagem de homem que precisamos estabelecer e que nos orienta a afirmar a necessidade de uma fundamentação ontológica da ética. "Somente então, com a antevisão da desfiguração do homem, chegamos ao conceito de homem a ser preservado. Só sabemos o que está em jogo quando sabemos que está em jogo. Como se trata não apenas do destino do homem, mas também da imagem do homem, não 
apenas de sobrevivência física, mas também da integridade de sua essência, a ética que deve preservar ambas, precisa ir além da sagacidade e tornar-se uma ética do respeito" (2006, p. 21).

O problema que destacamos das propostas transumanistas em relação ao aprimoramento humano, é que tais movimentos consideram a precariedade e vulnerabilidade da vida como algo negativo e, do ponto de vista ético, como algo moralmente inaceitável. Para os defensores do transumanismo, podemos e devemos nos livrar das amarras e da tirania da natureza através do uso de procedimentos tecnológicos e científicos. Os transumanistas não consideram a vulnerabilidade da vida como um valor intrínseco do ser, como Jonas evidenciou em sua obra. Por isso defendemos que, qualquer ameaça ou aposta, de forma direta ou indireta, a continuidade do ser, deve ser evitada e refletida eticamente.

Portanto, somente o homem é capaz de assumir a tarefa de garantir a existência e continuidade da vida, pois ele é o único ser cuja liberdade pode assumir a forma para agir com responsabilidade. De acordo com Paolo Becchi e Roberto F. Tibaldeo, "o aparecimento do homem na terra não constitui, apenas um aspecto adicional do mundo já variado de ser, porque em sua natureza algo qualitativamente diferente é revelado: o ser capaz de responsabilidade. Nisso consiste basicamente sua constituição ontológica, que é caracterizado por sua própria natureza "transanimal" e por uma forma de liberdade sem precedentes". (2015). Sendo assim, uma vez que a existência é confiada aos humanos, o ser humano é responsável em garantir as condições de vida e lutar contra as ameaças que poderiam causar o seu desaparecimento do mundo.

\section{Referências}

AGAR, Nicholas. Truly human enhancement: a philosophical defense of limits. Cambridge: MIT Press, 2013. 
BECCHI, Paolo; TIBALDEO, Roberto Franzini. Natura, natura umana, transumano: il contributo di Hans Jonas. Cosmopolis Rivista di Filosofia e teoria política, XII, 2015. Disponível em: https://www.researchgate.net/publication/304778572_Natura_natura_u mana_transumano_il_contributo_di_Hans_Jonas. Acesso em: 10 de outubro de 2017.

BOHLER, Dietrich. Princípio. In.: OLIVEIRA, Jelson; POMMIER, Eric. (Orgs.). Vocabulário Hans Jonas. Caxias do Sul: Educs, 2019.

BOSTRON, Nick. Human Reproductive Cloning from the Perspective of the Future. $2002 . \quad$ Disponível em: https://nickbostrom.com/views/cloning.html. Acesso em: 10 de setembro de 2019.

BOSTROM, Nick. Uma historia del pensamento transhumanista. Argumentos de Razón Técnica, no 14, pp. 157-191, 2011

COMÍN, Illana Giner. Introducción a la edición española. In: JONAS, Hans. Poder o impotência de la subjeticidad. Tradução de Illana Giner Comin. Coleção Pensamento Contemporâneo. Barcelona/Buenos Aires/México: Paidós, p.13-70, 2005.

FERRY, Luc. A revolução transumanista. Tradução de Éric R. R. Heneault. Barueri: Manole, 2018.

FM-2030. Are you transhuman? Monitoring and simulating your personal rate of growth in a rapidly changing world. New York: Warner Books, 1989.

GIACOIA JUNIOR, Oswaldo. Responsabilidade. In.: OLIVEIRA, Jelson; POMMIER, Eric. (Orgs.). Vocabulário Hans Jonas. Caxias do Sul: Educs, 2019.

HOTTOIS, Gilbert. Le transhumanisme est-il un humanisme? Bruxelles: Académie royale de Belgique, 2014.

HUXLEY, Julian. New botttles for new wine. London: Chatto and Windus, 1957.

JONAS, Hans. Ensaios filosóficos: da crença antiga ao homem tecnológico. Tradução de Wendell Evangelista Soares Lopes. São Paulo: Paulus, 2017. 
JONAS, Hans. Matéria, espírito e criação: dados cosmológicos e conjecturas cosmogônicas. Tradução de Wendell Evangelista Soares Lopes. Petrópolis: Vozes, 2010.

JONAS, Hans. Memorias. Traducción de Illana Giner Comín. Madri: Editorial Losada, 2005.

JONAS, Hans. O princípio responsabilidade: ensaio de uma ética para a civilização tecnológica. Trad. Marijane Lisboa, Luiz Barros Montez. Rio de Janeiro: Contraponto: Ed. PUCRio, 2006.

JONAS, Hans. O princípio vida: fundamentos para uma biologia filosófica. Trad. Carlos Almeida Pereira. Petrópolis: Vozes, 2004.

JONAS, Hans. Pensar sobre Dios y otros ensayos. Trad. Angela Ackermann. Barcelona: Herder, 1998.

JONAS, Hans. Técnica, medicina e ética: sobre a prática do princípio responsabilidade. Tradução do Grupo de Trabalho Hans Jonas da ANPOF. São Paulo: Paulus, 2013.

LOPES, Wendel Evangelista Soares. Hans Jonas e a diferença antropológica: uma leitura da biologia filosófica. Tese (Doutorado em Filosofia) - Universidade Federal de Minas Gerais, 2014.

MIRANDOLA, Giovanni Pico Della. Discurso sobre a dignidade do homem. Rio de Janeiro: Edições 70, 1989.

MONOD, Jean. O acaso e a necessidade. $4^{\mathrm{a}}$ ed. Petrópolis: Vozes, 1976.

OLIVEIRA, Jelson; MORETTO, Giovani; SGANZERLA, Anor. Vida, técnica e responsabilidade: três ensaios sobre a filosofia de Hans Jonas. São Paulo: Paulus, 2015.

PINSART, Marie-Genevière. Liberdade. In.: OLIVEIRA, Jelson; POMMIER, Eric. (Orgs.). Vocabulário Hans Jonas. Caxias do Sul: Educs, 2019.

SAVULESCU, J. "The human prejudice and the moral status of enhanced beings: what do we owe the Gods?". In: SAVULESCU, J.; BOSTROM, N. (org.). Human enhancement. Oxford: Oxford University Press, p. 211250, 2009. 